\title{
Year-round spatial distribution and migration phenology of a rapidly declining trans-Saharan migrant-evidence of winter movements and breeding site fidelity in European turtle doves
}

\author{
Yvonne R. Schumm ${ }^{1} \cdot$ Benjamin Metzger ${ }^{2} \cdot$ Eric Neuling $^{3} \cdot$ Martin Austad $^{4} \cdot$ Nicholas Galea $^{4} \cdot$ Nicholas Barbara $^{4}$. \\ Petra Quillfeldt ${ }^{1}$
}

Received: 24 June 2021 / Revised: 6 September 2021 / Accepted: 9 September 2021 / Published online: 13 October 2021

(c) The Author(s) 2021

\begin{abstract}
Populations of migratory bird species have suffered a sustained and severe decline for several decades. Contrary to nonmigratory species, understanding the causal mechanisms proves difficult (for migratory bird species) as underlying processes may operate across broad geographic ranges and stages of the annual cycle. Therefore, the identification of migration routes, wintering grounds, and stopover sites is crucial for the development of relevant conservation strategies for declining migrant bird species. We still lack fundamental data of the non-breeding movements for many migratory species, such as European turtle doves Streptopelia turtur, a trans-Saharan migrant. For this species, knowledge of non-breeding movements is mainly based on ringing data that are limited by a low recovery rate in Africa, and tracking studies with a strong bias towards individuals breeding in France. We used Argos satellite transmitters to obtain detailed year-round tracks and provide new insights on migration strategies and winter quarters, of turtle doves breeding in Central and Eastern Europe. The tracking data along with analysis of land cover data confirm previously assumed use of multiple wintering sites and the use of a wide range of forest and agricultural landscapes at the breeding grounds. Tracking data in combination with environmental parameters demonstrated that most environmental parameters and niche breadth differed between breeding and wintering grounds. "Niche tracking" was only observed regarding night-time temperatures. Furthermore, we provide evidence for breeding site fidelity of adult individuals and for home range size to increase with an increasing proportion of agricultural used areas.
\end{abstract}

\section{Significance statement}

The European turtle dove, a Palearctic-African migrant species, is one of the fastest declining birds in Europe. The rapid decline is presumed to be caused mainly by habitat modification and agricultural changes. Here, we represent data on migration strategies, flyways, and behavior on European breeding and African non-breeding sites of turtle doves breeding in Central and Eastern Europe equipped with satellite transmitters. Our results confirm the use of different migration flyways and reveal an indication for "niche switching" behavior in terms of environmental factors during the different annual phases. The migratory behaviors revealed by the tracking approach, e.g., prolonged stopovers during autumn migration in Europe overlapping with time of hunting activities, stopovers in North Africa during spring migration, or evidence for loop migration, are important protection-relevant findings, particularly for the Central-Eastern flyway, for which no tracking data has been analyzed prior to our study.

Keywords Argos satellite transmitter (PTT) · Migration routes · Satellite telemetry · Streptopelia turtur · Stopover sites · Winter quarters

Communicated by W. Wiltschko

Yvonne R. Schumm

Yvonne.R.Schumm@bio.uni-giessen.de

Extended author information available on the last page of the article

\section{Introduction}

Twice every year an estimated number of more than two billion birds, belonging to the Palearctic-African migration system, migrate between Europe and sub-Saharan Africa 
(Hahn et al. 2009). In general, these migrants travel between their European breeding and sub-Saharan non-breeding grounds crossing the Mediterranean Sea and the Sahara desert via several broad-scale migration corridors and flyways, formed by specific geographical structures and ecological barriers. Migration within this system strongly funnels along two major flyways, namely the Western flyway, over the Iberian Peninsula crossing the strait of Gibraltar to Northwest-Africa, and the Eastern flyway via the Balkan Peninsula and the Middle East (Briedis et al. 2020). A third migration route via the Apennine peninsula and across the strait of Sicily is the Central flyway (Marx et al. 2016).

One of the bird species migrating from Europe to the African Sahel zone is the European turtle dove Streptopelia turtur (hereafter turtle dove). It is the smallest member of the European Columbiformes and the only long-distance migrant among them. Formerly a widespread and common breeding bird species over a large part of the European Continent, Western Asia, and Northern Africa (Glutz von Blotzheim and Bauer 1987), the turtle dove has faced population declines over the past decades and is now listed as "Vulnerable" by the IUCN (BirdLife International 2019). In Europe, numbers have decreased by around $80 \%$ between 1980 and 2017 (PECBMS 2020). The major reasons for the population decline are presumed to be habitat modification and agricultural intensification at the breeding and wintering areas as well as potentially also on stopover sites used during migration (Browne and Aebischer 2004; Eraud et al. 2009; Fisher et al. 2018). Unsustainable legal and illegal hunting activities along the migration routes are further contributing to the decline (Fisher et al. 2018; Lormée et al. 2019).

Analyses of ring recoveries confirm that turtle doves migrate along all three aforementioned flyways. Ringing studies further found evidence for a migratory divide in Europe with Western European populations of turtle doves using the Western flyway and Central and Eastern European populations migrating along the Central or the Eastern flyway (Dimaki and Alivizatos 2014; Marx et al. 2016). However, sampling turtle dove populations across Europe did not reveal any genetic structure that would support discerned populations according to this migratory divide, but rather one large, panmictic population (Calderón et al. 2016). Furthermore, only $1.6 \%$ (14 out of 897 ) ring recoveries came from Sub-Saharan Africa (Marx et al. 2016), indicating that there is still a lack of knowledge regarding the wintering grounds and the exact flyways of turtle doves.

Advances in tracking techniques have started to shed more light onto the migration routes of turtle doves (Eraud et al. 2013; Lormée et al. 2016). However, so far there has been a strong bias of studies towards turtle doves breeding in France, which use the Western flyway, whereas detailed knowledge based on tracking of individuals migrating on the Central and Eastern flyway remains very limited.
As the seasonal movement patterns are not solely influenced by the internal state of organisms and biological factors, but also by external factors, i.e., the environment and underlying context (Nathan et al. 2008), we compared the environmental conditions at the European breeding and the sub-Saharan non-breeding region of turtle doves by selecting different environmental variables to describe and characterize the individual habitats of tracked birds. The environmental factors determining the distribution of migrants may differ between breeding and non-breeding areas (Ponti et al. 2020), depending on if migrants move in geographical space to track their favored environmental conditions to remain in a specific subset of preferred niche space, so-called "niche tracking" (van der Graaf et al. 2006; Tingley et al. 2009; Gómez et al. 2016). Alternatively, they may change their environmental niche ("niche switching") between periods of the annual cycle. If different aspects of seasonal movements reflect conservatism in ecological characteristics vs. seasonal changes, the conserved patterns may greatly inform related issues, such like habitat choice and timing of migration (Nakazawa et al. 2004).

We present findings of a satellite tracking study on turtle doves equipped with Argos transmitters during spring migration on Malta, located on the Central flyway, and during breeding season in two states of Germany, with hitherto unknown assignment to the possible flyways. In addition to the description of the different annual phases (breeding, spring and autumn migration, stopover, and wintering) of each tracked bird, we analyzed the favored environmental conditions at the breeding and wintering sites in order to test for niche overlap in the seasonal niches.

\section{Material and methods}

\section{Bird capture and transmitter deployment}

From 2016 to 2020, turtle doves were caught during stopover on their return migration in spring along the Central flyway on the Maltese islands $(n=8)$ using mist nets. In 2019 and 2020, turtle doves were caught during breeding time in two states of Germany (Central Germany: Hesse $(n=5)$ and Eastern Germany: Brandenburg $(n=3))$ using drop traps baited with a mix of cereal seeds (Table 1). It was not possible to record data blind, as our study involved individually marked animals in the field.

The sex was determined by molecular analysis based on collected feather or blood samples (Griffiths et al. 1998) and by characteristics of plumage (Demongin 2016). Birds were individually fitted with an Argos satellite tag (Solar $5 \mathrm{~g}$ PTT, Microwave Telemetry, USA), providing location fixes based on Doppler calculations, fixed as a wing-loop backpack using a 2-mm-wide Teflon ribbon (Ecotone, Poland) 
Table 1 Individual information of European turtle doves Streptopelia turtur equipped with Solar 5 g PTT Argos satellite tags during spring migration on Malta and during breeding period in Germany

\begin{tabular}{|c|c|c|c|c|c|c|c|c|}
\hline Bird ID & $\begin{array}{l}\text { Duty cycle } \\
\text { [ON/OFF] }\end{array}$ & $\begin{array}{l}\text { Deployment date } \\
\text { [dd.mm.yyyy] }\end{array}$ & $\begin{array}{l}\text { Catching loca- } \\
\text { tion [Lat, Long] }\end{array}$ & Sex & Body mass [g] & $\begin{array}{l}\text { Device weight [\% of } \\
\text { the birds' body mass] }\end{array}$ & $\begin{array}{l}\text { End data } \\
\text { transmission }^{\mathrm{a}}[\mathrm{dd} . \\
\text { mm.yyyy] }\end{array}$ & $\begin{array}{l}\text { Data trans- } \\
\text { mission } \\
\text { [days] }\end{array}$ \\
\hline \#161046 & $10 \mathrm{~h} / 48 \mathrm{~h}$ & 13.05 .2016 & $\begin{array}{l}\text { Malta } \\
35.95,14.38\end{array}$ & NA & 137 & 3.6 & 05.08.2017 & 450 \\
\hline \#161047 & $10 \mathrm{~h} / 48 \mathrm{~h}$ & 21.04 .2017 & $\begin{array}{l}\text { Comino } \\
36.01,14.34\end{array}$ & NA & 136 & 3.7 & 30.04 .2017 & 9 \\
\hline \#161048 & $10 \mathrm{~h} / 48 \mathrm{~h}$ & 22.04 .2017 & $\begin{array}{l}\text { Comino } \\
36.01,14.34\end{array}$ & $\mathrm{f}$ & 118 & 4.2 & 27.04.2018 & 370 \\
\hline \#161049 & $08 \mathrm{~h} / 15 \mathrm{~h}$ & 22.04 .2017 & $\begin{array}{l}\text { Comino } \\
36.01,14.34\end{array}$ & $\mathrm{~m}$ & 142 & 3.5 & 20.09 .2017 & 151 \\
\hline$\# 161050$ & $08 \mathrm{~h} / 15 \mathrm{~h}$ & 23.04 .2017 & $\begin{array}{l}\text { Comino } \\
36.01,14.34\end{array}$ & $\mathrm{~m}$ & 129 & 3.9 & 14.08 .2020 & 1209 \\
\hline \#181091 & $10 \mathrm{~h} / 48 \mathrm{~h}$ & 13.06.2019 & $\begin{array}{l}\text { Hesse } \\
50.49,08.92\end{array}$ & $\mathrm{f}$ & 160 & 3.1 & 25.09 .2020 & 470 \\
\hline \#181090 & $10 \mathrm{~h} / 48 \mathrm{~h}$ & 24.06 .2019 & $\begin{array}{l}\text { Brandenburg } \\
51.92,14.33\end{array}$ & $\mathrm{~m}$ & 160 & 3.1 & 26.09.2019 & 94 \\
\hline \#181092 & $10 \mathrm{~h} / 48 \mathrm{~h}$ & 25.06 .2019 & $\begin{array}{l}\text { Brandenburg } \\
51.92,14.33\end{array}$ & $\mathrm{~m}$ & 161 & 3.1 & 09.05 .2020 & 319 \\
\hline \#181089 & $10 \mathrm{~h} / 48 \mathrm{~h}$ & 25.06 .2019 & $\begin{array}{l}\text { Brandenburg } \\
51.92,14.34\end{array}$ & $\mathrm{f}$ & 158 & 3.2 & 20.10 .2019 & 117 \\
\hline \#200345 & $08 \mathrm{~h} / 15 \mathrm{~h}$ & 01.05 .2020 & $\begin{array}{l}\text { Comino } \\
36.01,14.34\end{array}$ & $\mathrm{f}$ & 125 & 4.0 & 02.05 .2020 & 1 \\
\hline \#200348 & $08 \mathrm{~h} / 15 \mathrm{~h}$ & 04.05 .2020 & $\begin{array}{l}\text { Comino } \\
36.01,14.34\end{array}$ & $\mathrm{f}$ & 132 & 3.8 & 22.06 .2020 & 49 \\
\hline \#200349 & $08 \mathrm{~h} / 15 \mathrm{~h}$ & 05.05 .2020 & $\begin{array}{l}\text { Comino } \\
36.01,14.34\end{array}$ & $\mathrm{~m}$ & 180 & 2.8 & 01.09 .2020 & 119 \\
\hline \#200351 & $08 \mathrm{~h} / 15 \mathrm{~h}$ & 05.06 .2020 & $\begin{array}{l}\text { Hesse } \\
50.44,08.55\end{array}$ & $\mathrm{~m}$ & 148 & 3.4 & 30.10 .2020 & 147 \\
\hline \#200352 & $08 \mathrm{~h} / 15 \mathrm{~h}$ & 07.06 .2020 & $\begin{array}{l}\text { Hesse } \\
50.44,08.55\end{array}$ & $\mathrm{f}$ & 155 & 3.2 & 07.10 .2020 & 122 \\
\hline \#200353 & $08 \mathrm{~h} / 15 \mathrm{~h}$ & 08.06 .2020 & $\begin{array}{l}\text { Hesse } \\
50.49,08.92\end{array}$ & $\mathrm{f}$ & 149 & 3.4 & 16.09 .2020 & 100 \\
\hline \#200350 & $08 \mathrm{~h} / 15 \mathrm{~h}$ & 13.06 .2020 & $\begin{array}{l}\text { Hesse } \\
50.44,08.55\end{array}$ & $\mathrm{~m}$ & 173 & 2.9 & 12.10 .2020 & 121 \\
\hline
\end{tabular}

${ }^{\text {a }}$ Transmission of locations stopped without known reasons or transmission manually terminated due to stable positions from the same (unhospitable) location for consecutive weeks

harness, following the method described by Lormée et al. (2016). The overall weight of the tracking device was below the $5 \%$ of the birds' body masses threshold, recommended in literature (Fair et al. 2010). Satellite tags deployed were programmed with a standard duty cycle of $10 \mathrm{~h} \mathrm{ON} / 48 \mathrm{~h}$ OFF or with a modified duty cycle of $8 \mathrm{~h}$ ON/15 h OFF (Table 1). All birds were released immediately after tagging at the location of capture.

The transmitters of the individuals \#161047 and \#200345 stopped recording 9 days and 1 day after tagging, respectively, while both birds were still on stopover on the Maltese Islands. These two individuals were probably killed by poachers. Individual \#200348 sent data for 49 days. However, within that time, she did not settle at a breeding site but crossed the sea between Sicily and Libya twice until data transmission stopped over the Mediterranean Sea (Supplementary Fig. 1n). These three turtle doves were excluded from all further analyses, resulting in a final data set of 13 tracked turtle doves.

\section{Handling of tracking data}

All location data as received from Argos of all location classes (LC: 3, 2, 1, 0, A, B) were automatically uploaded to Movebank (movebank.org) in their original projection (WGS84). We applied the "Douglas Filter" (Filter Method: Best Hybrid, Douglas et al. 2012) to remove erroneous data and afterwards checked for possible remaining outliers manually. These filtered location data were used when plotting the data in QGIS 2.18 (QGIS.org 2016). Tracks 
were displayed by using the "Points2One" plugin in QGIS (Kapusta 2015).

Locations obtained before deployment were used to estimate accuracy of the locations. The deviation of these locations $(n=63)$ was on average $2 \mathrm{~km}$, ranging from 0.1 to $10 \mathrm{~km}$.

To determine the different phases (i.e., breeding, migration, stopover, and wintering) in the annual cycle of the individuals, we used an approach similar to that described in Lormée et al. (2016): Clear switches in the pattern of the location data defined the onset and end of the different phases. Breeding phase was the period when an individual spent at least 45 days between April and September in one distinct area (Glutz von Blotzheim and Bauer 1987; Marx et al. 2016). We defined the pre-migratory movements as movements to a distinct site, onwards called post-breeding site, where the period (minimum of 10 days) after likely nesting was spent before the onset of migration (Pagen et al. 2000; Vitz and Rodewald 2007). The onset of molt migration or autumn migration was specified as soon as movements $>100 \mathrm{~km}$ in direction to the wintering grounds, e.g., southwards, south westerly or south easterly, occurred. Molt migration is the temporal overlap in the molt and migration life history stages (Tonra and Reudink 2018). Since there is no uniform pattern whether molt migration occurred, as some individuals presumably molt the first inner primaries on or near their breeding sites, while others stop during autumn migration to molt en route (Demongin 2016; Pillar et al. 2016), the term "autumn migration" used throughout the paper includes possible molt migration (Pillar et al. 2016; Table 2). A stopover site was defined as consecutive set of locations overlapping spatially for at least three days during migration period and being at least $100 \mathrm{~km}$ away from the breeding site. Molt of the first inner primaries at stopover sites was assumed if the individuals staged after leaving the breeding site for at least 21 days (Mallet-Rodrigues 2012) in Europe before October (Demongin 2016). These sites are referred to as "stopover molt sites" (Pillar et al. 2016). If an individual stayed for at least 14 consecutive days in one distinct area south of $20^{\circ} \mathrm{N}$ (Glutz von Blotzheim and Bauer 1987; Eraud et al. 2013), this was specified as the start of the wintering period.

Epanechnikov kernels (95\% and 50\% kernel utilization distributions "KUD"; Epanechnikov 1969) of filtered localizations received during the breeding and wintering period were calculated in R with the function the "kernelUD" in the package "adehabitatHR" (Calenge 2015). We used a generic grid of 200 cells and the smoothing parameter was estimated with a href parameter. The area covered by the individual birds was estimated with the R package "sp Classes and Methods for Spatial Data" (Pebesma 2020).

To characterize the land cover in the occupied habitats the 95\% KUDs were clipped in QGIS 2.18 with raster land cover data and the percentages of different land covers classes in the 95\% KUDs were calculated. For European breeding grounds, land cover data were based on Corine Land Cover CLC 2018 v.2020_20u1 (Copernicus Land Monitoring Service 2021) and for African wintering grounds on ESA CCI Land Cover S2 prototype LC 20 m map of Africa 2016 (ESA CCI Land Cover project 2021).

Only complete periods in the life cycle of the birds were used in the detailed analyses of durations. To determine whether migratory movements of the turtle doves occurred during the night or day, we calculated for each location fix of complete autumn $(n=7)$ and spring tracks $(n=5)$, when the morning and evening civil twilight had been by using the function "crepuscule" (R package maptools, Bivand et al. 2020). With the "crepuscule" function we estimated when the geometric center of the sun was $6^{\circ}$ below the horizon in the morning (civil dawn) and in the evening (civil dusk). Night-time was defined as the period of time between civil dusk and the consecutive civil dawn (Zúñiga et al. 2016). Fixes included in this analysis were at least $1 \mathrm{~h}$, but not more than $6 \mathrm{~h}$, apart from each other and only considered when individuals were actively migrating ( $n=189$ pairs of fixes). If the direct distance between two consecutive fixes was more than $25 \mathrm{~km}$ (mean flight speed during migration is approx. $50 \mathrm{~km} / \mathrm{h}$; Lormée et al. 2016), active migratory movement was presumed ( $n=51$ pairs of fixes) and classified as night-time, daytime, or between (i.e. one of the fixes during night- and the other one during daytime). From the fixes during active migratory movement ( $n=51$ pairs of fixes), the mean flight speed was calculated.

To compare environmental habitat parameters at breeding and wintering grounds, nine habitat parameters were obtained through the Environmental Data Automated Track Annotation System (Env-DATA, Dodge et al. 2013; interpolation: bilinear) on Movebank for filtered positions of those turtle doves from which we obtained locations at both wintering and breeding grounds $(n=5$; Table 2$)$. Locations received during winter movements (i.e., movement between different wintering sites), stopovers, and active migration were excluded. The environmental data included parameters from MODIS land: net photosynthesis (PsnNet), gross primary productivity (GPP), total evapotranspiration, enhanced vegetation index (EVI), daily land surface temperature day and night, and vegetation index (NDVI) as well as the parameters elevation (ETOPO1) and human population density adjusted (SEDAC GPW V3 and GRUMP V1 GRUMP 
Table 2 Details of the migration schedule of 13 European turtle doves Streptopelia turtur equipped with satellite tags from 2016 to 2020

\begin{tabular}{|c|c|c|c|c|c|c|c|c|c|}
\hline \multirow[t]{2}{*}{ Bird ID } & \multicolumn{4}{|c|}{ Spring migration } & \multirow{2}{*}{$\begin{array}{l}\text { Breeding } \\
\text { Duration in days } \\
\text { [dd.mm to } \\
\text { dd.mm] }\end{array}$} & \multicolumn{3}{|l|}{ Autumn migration } & \multirow{2}{*}{$\begin{array}{l}\text { Wintering } \\
\text { Duration in days } \\
\text { [dd.mm to dd.mm] }\end{array}$} \\
\hline & Year & $\begin{array}{l}\text { Duration in days } \\
\text { [dd.mm to dd.mm] }\end{array}$ & $\begin{array}{l}\text { No. stopover } \\
\text { Africa } \\
\text { [country:days] }\end{array}$ & $\begin{array}{l}\text { No. stopover } \\
\text { Europe } \\
\text { [country:days] }\end{array}$ & & $\begin{array}{l}\text { Duration in days } \\
\text { [dd.mm to } \\
\text { dd.mm] }\end{array}$ & $\begin{array}{l}\text { No. stopo- } \\
\text { ver Europe } \\
\text { [country:days] }\end{array}$ & $\begin{array}{l}\text { No. } \\
\text { stopover Africa } \\
\text { [country:days] }\end{array}$ & \\
\hline \multirow[t]{2}{*}{ \#161046 } & 2016 & {$\left[\mathrm{ST}^{\mathrm{a}}-22.05\right]$} & & & 116 [22.05-14.09] & 64 [14.09-16.11] & 0 & $\begin{array}{l}4 \text { [LY:12, } \\
\text { ML:6, } \\
\text { NE:13;4] }\end{array}$ & $156[16.11-20.04]$ \\
\hline & 2017 & 23 [20.04-12.05] & 1 [LY:9] & 0 & {$\left[12.05-\mathrm{ET}^{\mathrm{a}}\right]$} & & & & \\
\hline \multirow[t]{2}{*}{ \#161048 } & 2017 & [ST-18.05] & & & 114 [18.05-08.09] & 16 [08.09-23.09] & 1 [GR:3] & 0 & 213 [23.09-23.04] \\
\hline & 2018 & [23.04-ET] & & & & & & & \\
\hline \#161049 & 2017 & [ST-20.06] & & 2 [IT:18; 16] & 63 [20.06-21.08] & [21.08-ET] & $1\left[\mathrm{HU}: 25^{\mathrm{c}}\right]$ & & \\
\hline \multirow[t]{4}{*}{$\# 161050$} & 2017 & [ST-05.05] & & & $\begin{array}{c}117[05.05- \\
29.08]^{\mathrm{b}}\end{array}$ & 18 [29.08-15.09] & 1 [IT:4] & 1 [NE:6] & 207 [15.09-09.04] \\
\hline & 2018 & 23 [09.04-01.05] & 1 [TN:15] & 0 & $\begin{array}{c}134[01.05- \\
11.09]^{\mathrm{b}}\end{array}$ & 7 [11.09-17.09] & 0 & 0 & 209 [17.09-13.04] \\
\hline & 2019 & 20 [13.04-02.05] & 1 [TN:8] & 0 & $\begin{array}{c}131[02.05- \\
09.09]^{\mathrm{b}}\end{array}$ & 14 [09.09-22.09] & 0 & 1 [MA:6] & 205 [22.09-13.04] \\
\hline & 2020 & 21 [13.04-03.05] & 1 [DZ:10] & 0 & [03.05-ET] & & & & \\
\hline \multirow[t]{2}{*}{ \#181091 } & 2019 & & & & [ST-01.09] & 35 [01.09-05.10] & 2 [FR:12, ES:6] & 0 & 206 [05.10-27.04] \\
\hline & 2020 & 50 [27.04-15.06] & $\begin{array}{l}3 \text { [MR:6, } \\
\text { MA:16; 4] }\end{array}$ & 0 & 76 [15.06-29.08] & [29.08-ET] & 2 [FR:5;14] & & \\
\hline \#181090 & 2019 & & & & [ST-27.08] & {$[27.08-\mathrm{ET}]$} & 1 [HU:13] & 1 [LY:6] & \\
\hline \multirow[t]{2}{*}{ \#181092 } & 2019 & & & & [ST-13.09] & 22 [13.09-04.10] & 1 [HU:3] & 2 [LY:6, NE:3] & 206 [04.10-26.04] \\
\hline & 2020 & [26.04-ET] & & & & & & & \\
\hline \#181089 & 2019 & & & & [ST-05.08] & [05.08-ET] & $\begin{array}{r}2 \text { [SK:11, } \\
\text { HU:12] }\end{array}$ & 2 [TN:5, DZ:6] & \\
\hline \#200349 & 2020 & [ST-09.05] & & & [09.05-ET] & & & & \\
\hline \#200351 & 2020 & & & & [ST-05.09] & [05.09-ET] & 1 [FR:15] & & \\
\hline \#200352 & 2020 & & & & [ST-29.08] & [29.08-ET] & 2 [FR:7, IT:20] & 1 [TN:5] & \\
\hline \#200353 & 2020 & & & & [ST-01.09] & [01.09-ET] & 1 [ES:9] & & \\
\hline \#200350 & 2020 & & & & [ST-31.07] & [31.07-ET] & $\begin{array}{c}2 \text { [GE: } 24^{\mathrm{c}}, \\
\mathrm{ES}: 18]\end{array}$ & 1 [DZ:14] & \\
\hline
\end{tabular}

${ }^{\text {a }} S T$, start of data transmission; $E T$, end of data transmission

${ }^{\mathrm{b}}$ Including time spent at the post-breeding site (see Supplementary Fig. 2)

${ }^{\mathrm{c}}$ Stopovers at stopover molt sites (see Supplementary Fig. 1f, k)

2000). These parameters were selected as they likely influence the habitat selection of turtle doves and had a sufficient data coverage for both breeding and wintering sites.

Statistical analyses were conducted using R 3.4.1 (R Development Core Team 2018). Means \pm SE for the environmental parameters for each individual are given in Table 3 . To compare the aforementioned environmental habitat parameters at the different stages (breeding and wintering), a principal component analysis (PCA) was performed for every single individual as well as for all individuals together. The PCA extracted two significant components PC1 and PC2. Habitat niche plots were created from the two dimensions of the habitat (PC1 and PC2) using kernel densities function calculated in R with the function " $k d e 2 d$ " in the MASS package (Venables and Ripley 2002).

\section{Results}

Transmitters operated for 291 days on average ( $n=13$ turtle doves, Table 1), resulting in 19,482 filtered location fixes during 18 breeding (hereof seven complete) and seven complete wintering periods, 12 migration cycles in spring (hereof five complete), and 15 in autumn (seven complete) as well as 39 stopovers of which 2 are likely stopover molt sites (Fig. 1; Table 2). 


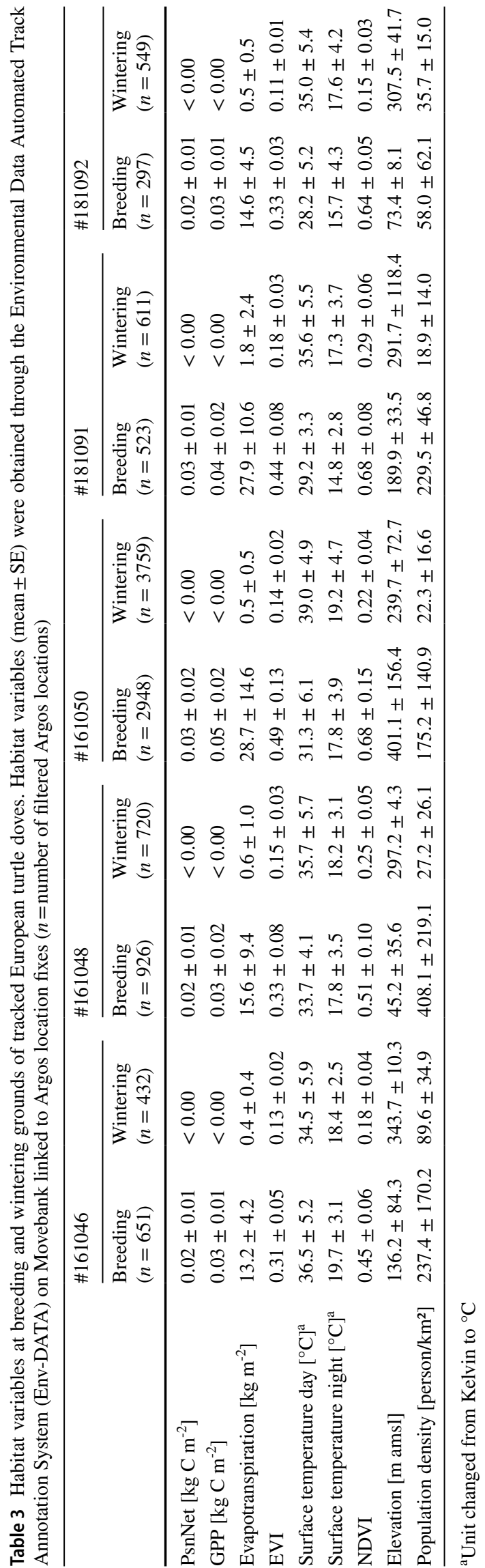

\section{Breeding period and post-breeding areas}

The turtle doves arrived at their breeding grounds between 1 . May and 20. June (median 18. May, $n=10$ ) and spent a total of 63-134 days (median 107.3 days, $n=7$ ) at the breeding grounds (Table 2). Breeding grounds of individuals tagged during spring migration on Malta were located in Italy (\#161046, \#161050, and \#200349), Bulgaria (\#161048), and Slovakia (\#161049; Supplementary Fig. 1).

Individuals $(n=8)$ tagged at the beginning of the breeding season in Germany stayed in the area where they were caught during the ongoing breeding season (Supplementary Fig. 1). The home range (95\% KUD) used by the turtle doves ( $n=18$ breeding sites from 13 individuals) was on average $496 \pm 335 \mathrm{~km}^{2}\left(\min 263 \mathrm{~km}^{2}\right.$ to $\left.\max 1554 \mathrm{~km}^{2}\right)$ and the core area (50\% KUD) was $39 \pm 29 \mathrm{~km}^{2}$ (min $14 \mathrm{~km}^{2}$ to $\max 121$ $\mathrm{km}^{2}$ ). Land cover in the 95\% Epanechnikov kernels varied per breeding area and individual. In total 35 of 44 Corine Land Cover classes occurred in the breeding areas (Supplementary Table 1). Land cover classes that were present in every single turtle dove breeding habitat were non-irrigated arable land $(29.4 \pm 15.5 \%$ of the $95 \%$ KUD), broadleaved forest $(20.9 \pm 19.5 \%)$, discontinuous urban fabric $(4.6 \pm 2.4 \%)$, and industrial or commercial units $(1.0 \pm 0.3 \%$; Fig. 2). The size of home ranges (95\% KUD) increased with a higher percentage of agricultural areas (Supplementary Table 1) as land cover in the $95 \%$ kernel, while there was no significant relation between home range size and the proportion of forest and seminatural areas (GLM: agricultural areas: $F_{1,10}=5.47, p=0.041$; forest and seminatural areas: $\left.F_{1,10}=3.53, p=0.090\right)$. The same applied for the size of core areas (GLM: agricultural areas: $F_{1,10}=5.02, p=0.049$; forest and seminatural areas: $F_{1,10}=3.87, p=0.078$ ).

Turtle doves for which we had data from the breeding grounds for consecutive years ( $n=3$; \#161046, \#161050, and \#181091) showed high site fidelity, i.e., returned to the exact same breeding area (Supplementary Fig. 1a, b, d).

The male individual \#161050 performed short pre-migratory movements $(<1$ day) into a defined post-breeding site around $20-30 \mathrm{~km}$ north-easterly to its breeding site (Supplementary Fig. 2), where it stayed for 39, 18, and 38 days in 2017,2018 , and 2019 , respectively, before starting the autumn migration. The other birds, stayed in their breeding areas until they started autumn migration, but individuals \#161049 and \#200350 moved to stopover molt sites for a prolonged period in more southern latitudes within Europe (Table 2, Supplementary Fig. 1f, k), indicating a stopover molt migration for these individuals.

\section{Autumn migration}

Turtle doves left their breeding areas between 31. July and 14. September (median 30. August, $n=15$ ). The overall 


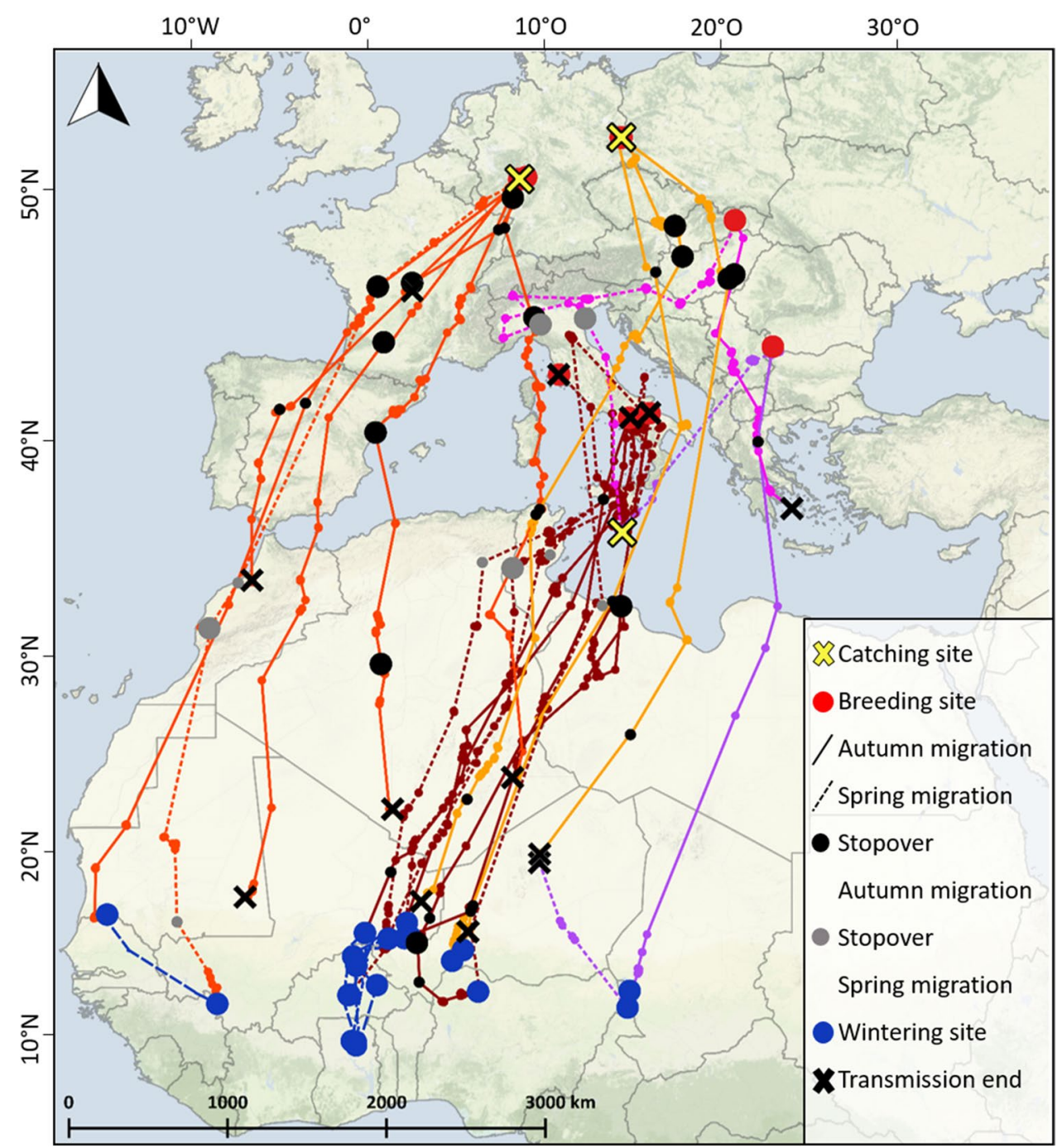

Fig. 1 Satellite tracks of 13 European turtle doves Streptopelia turtur during migration between European breeding (red circles) and African wintering grounds (blue circles). Tracks are given in different colors corresponding to different countries individuals had their breeding sites in: orange $=$ Germany $($ dark orange $=$ Hesse, Central Germany; light orange $=$ Brandenburg, Eastern Germany); dark red=Italy; pink =Slovakia: purple $=$ Bulgaria . Detailed tracks for single individuals can be found in Supplementary Fig. 1. Autumn migration is shown as solid line and spring migration as dashed line. Location fixes (based on Doppler locations) received during migration are

duration of the autumn migration including stopovers was 7-64 days (median 25.1 days, $n=7$ ), with a total stopover duration between 0 and 35 days (median 11.9 days, $n=7$ ). Stopovers were taken in $57.1 \%$ of autumn migrations in Europe (median 4 days, $n=7$ ) and in $57.1 \%$ in Africa (median 8 days, $n=7$, Table 2, Supplementary Fig. 3). However, considering the data of all tracked individuals, i.e., partial tracks included, several birds ( 3 of 4 individuals in the Western flyway and 4 of 8 in the Central-Eastern flyway) made prolonged post-breeding stopovers ( $>10$ days) shown as circles in the background of the track lines. Winter movements are displayed in dashed, blue lines. Black circles correspond to stopover sites during autumn migration and gray circles to stopover sites during spring migration. Circle size corresponds to stopover duration: Small circle $\leq 10$ days and big circle $>10$ days. Background colors indicate the terrain and gray lines indicate national borders (background map: Stamen terrain (map tiles by Stamen Design: http://maps.stamen.com; data by OpenStreetMap: www.openstreet map.org))

in Europe after leaving their breeding site (Table 2; Fig. 1). Prolonged stopovers were mainly made in Europe (58.8\% of stopovers; 10 of 17 stopovers) and less often in Africa (23.1\%; 3 of 13 stopovers).

Of the 12 turtle doves four individuals (\#181091, \#200351, \#200353, and \#200350), all with breeding grounds in Hesse, started in south-westerly direction. The two females \#181091 and \#200353 crossed the Mediterranean Sea at or close to the strait of Gibraltar, while the two males \#200351 and \#200350 crossed the Mediterranean Sea 
Fig. 2 Proportional occurrence [\%] of Corine Land Cover classes (Copernicus Land Monitoring Service 2021) in 95\% Epanechnikov kernels of satellite-tracked European turtle doves Streptopelia turtur at different breeding grounds. a Bulgaria (\#161048), b Slovakia (\#161049), c Southern Italy (\#161046 and \#161050), d Central Italy (\#200349), e Central Germany (\#181091, \#20035, \#200352, \#200353, and \#200350), f Eastern Germany (\#181090, \#181092, and \#181089). Only land cover classes accounting for a fraction of more than $1 \%$ are shown. All remaining classes $<1 \%$ have been summed up to " $\mathrm{O}$ : others." Further details to the other classes can be found in Supplementary Table 1
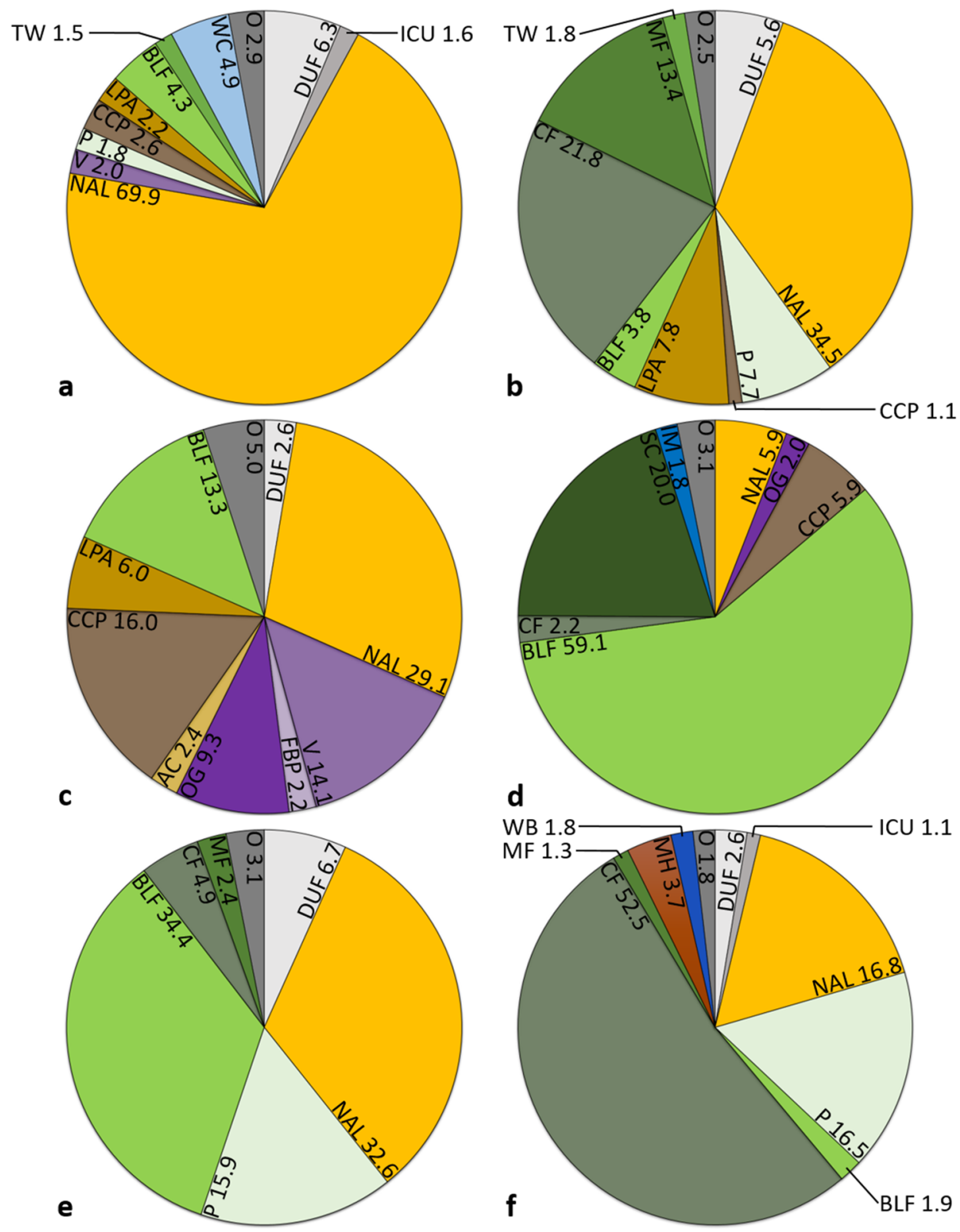

$\square$ DUF: discontinuous urban fabric
$\square$ ICU: industrial or commercial units
$\square$ NAL: non-irrigated arable land
$\square$ v: vineyards
$\square$ FBP: fruit trees \& berry plantations
$\square$ OG: olive groves
$\square$ P: pastures

AC: annual crops associated with permanent crops

SC: sclerophyllous vegetation CP: complex cultivation patterns PA: land principally occupied by agriculture $\square$ BLF: broad-leaved forest CF: coniferous forest

MF: mixed forest

$\mathrm{MH}$ : moors and heathland further east and therefore had a longer sea crossing (Supplementary Fig. 1j, k). The remaining turtle dove with breeding ground in Hesse (\#200352) migrated south over Corsica and Sardinia. Individuals breeding in Italy (\#161046 and \#161050) migrated along the Central flyway. Turtle doves with breeding grounds in Brandenburg (\#181090, \#181092, and \#181089) migrated first in a south-easterly direction to stopover sites in Eastern Europe and from there changed in a more south-westerly direction. Turtle doves breeding in Eastern Europe (\#161048 and \#161049) started their autumn migration in a southern direction over mainland and islands of Greece (Fig. 1, Supplementary Fig. 3).

Overall, turtle doves in our study were largely nocturnal migrants. The majority of location fixes $(81.8 \%)$ during active migratory movements were recorded during the night, compared to $9.1 \%$ during daytime and $9.1 \%$ between. 

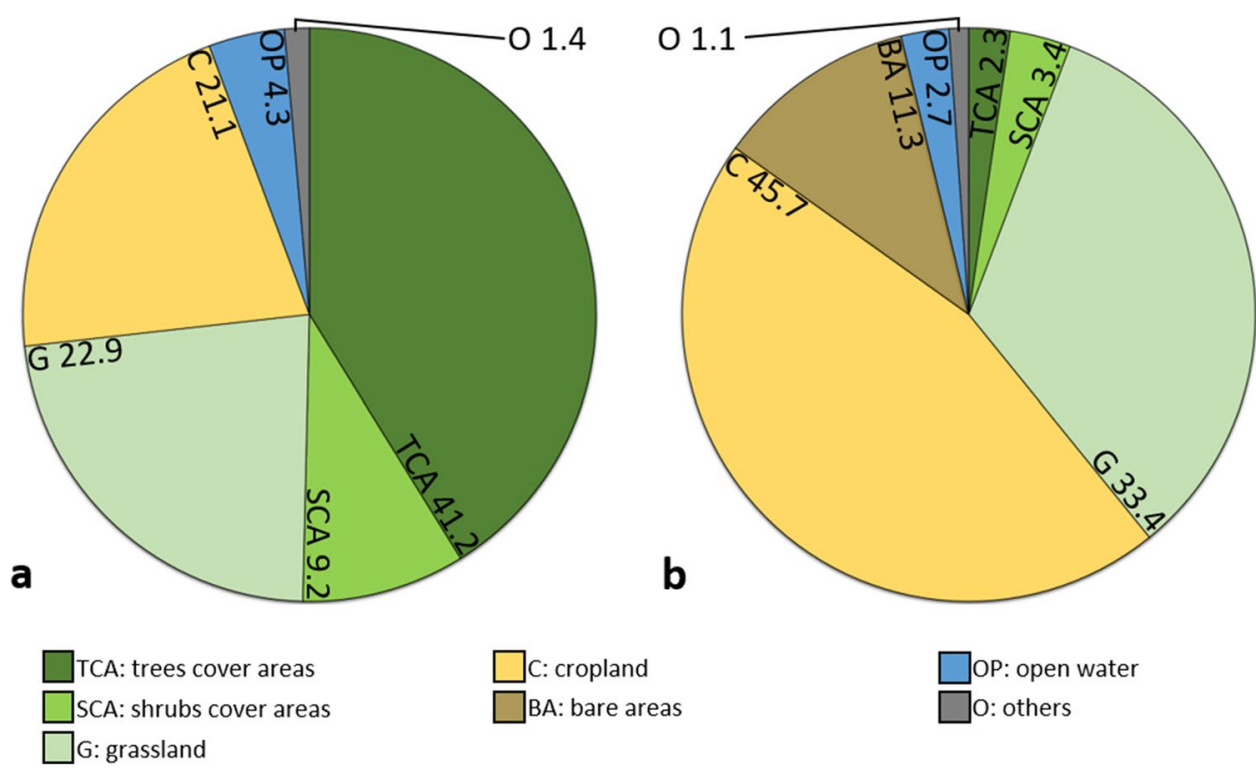

Fig. 3 Proportional occurrence [\%] of ESA CCI Land Cover classes (ESA CCI Land Cover project 2021) in 95\% Epanechnikov kernels of satellite-tracked European turtle doves Streptopelia turtur at different wintering grounds. a Western part of Western Africa. Individual \#181091 using the Western flyway and wintering in Senegal and South-Western Mali. b Central and Eastern parts of Western Africa.

The mean flight speed during the active migration was $45.7 \pm 12.8 \mathrm{~km} / \mathrm{h}$.

We lost most of our tagged individuals during autumn migration $(61.5 \%, 8$ of 13 individuals) compared to the other annual stages (wintering 0\%, spring migration: $15.4 \%$ and breeding: $23.1 \%)$.

\section{Wintering period}

Five of our satellite-tracked turtle doves arrived at their wintering grounds. The birds spent 156-213 days (median 200.3 days, $n=7$ ) wintering after arriving between 15 . September and 16 . November (median 2. October, $n=7$ ). Turtle doves overwintered in Western and Central Africa south of the Sahara (Figs. 1 and 3). While one individual (\#161046) spent the entire wintering period at one wintering site (Supplementary Fig. 1b), the other four individuals used multiple (2-6) distinct wintering sites with a southward shift during the wintering period. The $95 \%$ KUD of wintering sites used by the turtle doves ( $n=20$ wintering sites) was on average $65 \pm 154 \mathrm{~km}^{2}$ (min $18 \mathrm{~km}^{2}$ to $\max 510 \mathrm{~km}^{2}$ ) and the $50 \%$ KUD was $5 \pm 21 \mathrm{~km}^{2}\left(\min 1 \mathrm{~km}^{2}\right.$ to $\left.\max 67 \mathrm{~km}^{2}\right)$. From one individual (\#161050), we have locations from the wintering period for consecutive years. While its wintering duration is quite consistent (Table 2), the wintering localities varied between the wintering periods (Supplementary Fig. 1a).

A mix of crop- and grassland, likely used for foraging, and tree and shrub covered areas, presumably used as
Individuals \#161046, \#161048, \#161050, and \#181092 using the Central-Eastern flyway and wintering in Cameroon, Nigeria, Niger, Mali, Burkina Faso, and Ghana. Only land cover classes accounting for a fraction of more than $1 \%$ are shown. All remaining classes $<1 \%$ have been summed up to "O: others." Further details to the other classes can be found in Supplementary Table 2

resting and roosting sites, mainly characterized land cover at the wintering sites. Open water was available at all wintering areas (Fig. 3, Supplementary Table 2). Remarkably, we observed a much higher proportion of tree cover area (41.2\%) at the wintering sites of individual \#181091 (migrating along the Western flyway) compared to the other four turtle doves $(2.3 \pm 1.9 \%$ tree cover), which used the CentralEastern flyway and spend the wintertime in the Eastern parts of Western Africa.

\section{Spring migration}

The turtle doves started their spring migration between 9. April and 5. May (median 18. April, $n=7$ ). The duration of the spring migration including stopovers was 20-50 days (median 27.4 days, $n=5$ ). Stopovers lasted 8-26 days (median 13.6 days, $n=5$ ). African stopover sites were located in Mauritania, Morocco (Western flyway) and Algeria, Libya, and Tunisia (Central-Eastern flyway). None of the five individuals of which we have a complete spring migration track staged in Europe (Table 2, Supplementary Fig. 3). However, \#161049 from which we have a partial track of its spring migration made two stopovers in Italy, which lasted 18 and 16 days, before reaching its Slovakian breeding ground (Supplementary Fig. 1f). Individual \#161046 showed overshooting behavior during spring migration, i.e., first flying further north before returning to its breeding ground (Supplementary Fig. 1b). The three 
Fig. 4 Habitat niches of satellite-tracked European turtle doves Streptopelia turtur $(n=5)$ for wintering (blue) and breeding (red) grounds. Obtained from Argos-positions and kernel densities of principal component scores of environmental parameters $(n=9)$ obtained through the Environmental Data Automated Track Annotation System (Env-DATA) on Movebank. PC1 (eigenvalue 5.34) was determined mainly by the five variables (PsnNet, NDVI, EVI, GPP, and Evapotranspiration) and PC2 (eigenvalue 1.37) mainly by the surface temperature at night

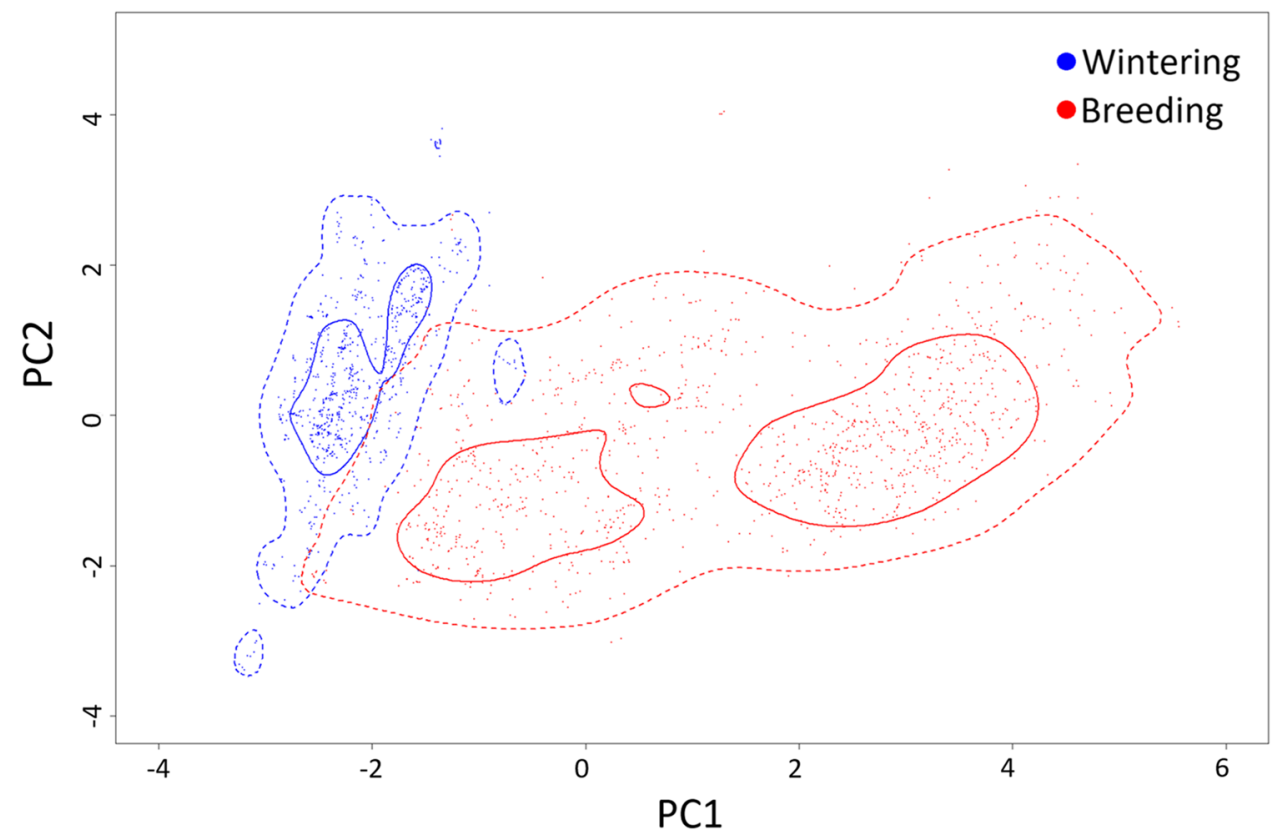

individuals we have complete spring migration tracks following the Western (\#181091) and Central flyway (\#161046 and \#161050) for autumn migration followed a very similar route for spring migration (Fig. 1). The partial migration tracks of individuals \#161048 and \#161049 following the Central flyway for spring migration and a flyway further to the east during autumn migration, suggesting a clockwise loop migration (Supplementary Fig. 1c, f).

Similarly to autumn, turtle doves migrated mainly during night-time (77.8\%). The mean flight speed during the active spring migration $(50.7 \pm 12.6 \mathrm{~km} / \mathrm{h})$ was not significantly faster than during autumn migration (independent $t$-test: $t=-0.53, d f=38, p=0.601$ ).

\section{Niche description approach}

Environmental parameters differed between breeding and wintering grounds (Table 3). The PCA for all individuals combined extracted two significant components: PC1 (eigenvalue 5.34) was determined mainly by the five variables, which are related to vegetation and biomass production (PsnNet, NDVI, EVI, GPP, and Evapotranspiration) and PC2 (eigenvalue 1.37) mainly by the surface temperature at night (Fig. 4, Supplementary Table 3 ).

The significant components extracted by the PCA differed slightly when single individuals were analyzed separately. PC1 was characterized for all single individuals mainly by PsnNet, NDVI, EVI, GPP, and Evapotranspiration. For the individuals \#161046, \#161048, and \#181092 additionally by elevation and for individual \#181091 also by the population density and surface temperature during the day. PC2 of all individuals was mainly determined by the surface temperature at night and for the individuals \#161046, \#161048, and \#181092 additionally by the daytime surface temperature and for \#181091 by elevation (Supplementary Table 3).

When comparing the ecological niches based on the tested parameters, turtle doves showed a change in environmental conditions represented by PC1 between the winter and breeding season, with the $95 \%$ kernels of the single individuals and combined data of the PCs hardly overlapping and the 50\% kernels not overlapping (Fig. 4, Supplementary Fig. 4), indicating different occupied niches in breeding and wintering sites with respect to vegetation and biomass production. However, PC2 (temperature, especially at nighttime) did not differ remarkably.

\section{Discussion}

Year-round data from our satellite transmitters allowed us to trace the timing and route followed by turtle doves from breeding grounds in Italy, Germany, Bulgaria, and Slovakia to the sub-Saharan wintering regions and vice versa, and to compare parameters of the breeding and wintering sites.

\section{Breeding and wintering areas}

The turtle dove breeding season starts immediately after arrival on the breeding grounds (Browne and Aebischer 2001). Assuming a total brood duration of around 45 days (Glutz von Blotzheim and Bauer 1987) and considering the average number of days (107) tracked individuals spent at the breeding areas, not more than two broods are possible. 
For some individuals spending even fewer days (\#161049: 63; \#181091: 76) in the breeding area, only one brood was possible. One of the main findings comparing the British population during the 1960s and 1990s was that turtle doves curtailed their breeding season, which ties in with a reduction of nesting attempts and productivity per pair (Browne and Aebischer 2001, 2003, 2004). Our results indicate that the time spent in breeding areas may have shortened for turtle doves all over Europe.

For the first time, mean size of home ranges and core areas (496 and $39 \mathrm{~km}^{2}$, respectively) could be calculated based on satellite tracking data. Glutz von Blotzheim and Bauer (1987) state that turtle doves often move 3-6 km or more from their nesting site for foraging. Even greater foraging distances, sometimes $>10 \mathrm{~km}$, were recorded (Browne and Aebischer 2001). Home ranges based on $100 \%$ minimum convex polygons (MCPs) of radio-tagged turtle doves in Britain were between $<1$ and $11.30 \mathrm{~km}^{2}$ (Browne and Aebischer 2001) and based on $90 \%$ MCPs $0.86 \pm 0.16 \mathrm{~km}^{2}$ (Dunn et al. 2020). Our calculated home range areas seem far larger than these ones. Differences might be due to varying calculation methods: On one hand, radio-transmitters are constrained by line-of-sight range between transmitter and receiver, easily leading to missed fixes during foraging trips. On the other hand, satellite data have larger error ranges due the Doppler method, possibly leading to the larger size of calculated home ranges. In addition, we calculated the KUD sizes based on fixes received during the entire time individuals were at their breeding grounds, while Dunn et al. (2020) calculated home ranges derived solely from fixes during incubation and chick stage. As habitat use of turtle doves differs during the breeding season (Browne and Aebischer 2001; Mansouri et al. 2019), different foraging areas used over the seasonal progress may have added up in our calculation.

It is suggested that individual turtle doves are not sitefaithful (Browne and Aebischer 2001; Dunn and Morris 2012). In contrast, all our turtle doves returning to the breeding grounds $(n=3)$ returned to the same breeding site occupied in the previous year. For \#161050, this was the case for four consecutive years. Tracking results therefore propose that adult turtle doves are highly faithful to their breeding sites.

In general terms, turtle doves nest in trees or bushes in a landscape characterized by a patchy habitat mosaic of open land, nearby to wooded areas and an adjacent water source (Lutz 2007; Fisher et al. 2018). Habitat selection patterns and habitat requirements were investigated by numerous studies mainly based on observational absence and presence data (Supplementary Table 4). These studies show that turtle doves occur over a wide range of forest and agricultural landscapes, depending on the availability of certain habitat types at the regional level, and that nesting and feeding habitats can be very diverse, depending on their nature (agricultural or natural), location, and time (Hanane 2012; Dias et al. 2013; Mansouri et al. 2019). Unlike the aforementioned studies, based on predetermined areas, e.g., grid squares, we checked the land cover in the actually used habitats according to the satellite tracking data. Our results support that habitat composition varies between different locations, e.g., preponderance of coniferous forest in Brandenburg, broadleaved forest in Hesse or olive groves in Italy (Fig. 2, Supplementary Table 1). Our land cover analysis showed that land cover types suitable for nesting activities (e.g., forests, olive groves, or shrubs) and areas most likely used for foraging (e.g., non-irrigated arable land, pastures, crop cultivations, or heathland) were present in every home range. This reinforces the assumption that the close proximity of suitable nesting and feeding areas is a key requirement for good quality habitats (Browne et al. 2004; Dias et al. 2013). Our findings indicate that a higher proportion of agricultural areas within the home range leads to an increase in home range size. This is in line with Dunn et al. (2020), associating small home ranges with a high proportion of non-farmed habitats and Chiatante et al. (2020), reporting that areas with a high proportion of crops were avoided. As large areas of the intensively farmed arable landscape are not suitable for feeding, those breeding turtle doves with a high proportion of intensively farmed arable land within their home range are forced to forage over large distances to reach good quality food resources. It is likely that the long distances covered affect the adults' body condition throughout the breeding season, and hence may negatively influence their overall breeding performance (Browne and Aebischer 2001). It must be noted that land cover categories used in the aforementioned studies and in our study mainly describe landscape types, but do not consider management procedures. Breeding numbers of turtle doves show an overall decline particularly from the 1970s onwards (Fisher et al. 2018). While there was no major land cover type change in Europe between 1950 and 2000 (Gerard et al. 2010), many agricultural and silvicultural management procedures have been modified drastically (Baessler and Klotz 2006; Dallimer et al. 2009; Wesche et al. 2012; EEA 2020). Therefore, future studies should take into account information about agricultural and silvicultural management, such as the use of herbicides, conventional or organic farming, timing of harvest, understorey, or forest margin management, to be able to draw a more precise picture of turtle dove habitat requirements.

At their winter quarters, turtle doves are also susceptible to agricultural changes, e.g., increased cultivation, overgrazing, and cutting of trees (Lutz 2007; Fisher et al. 2018). It was shown that the overwinter survival of adult turtle doves is strongly related to the cereal production at the winter quarters (Eraud et al. 2009). Suitable wintering habitats appear to 
be defined by an abundant food supply, an accessible water source and large trees or patches of woodland for roosting. If one of these key factors is absent, the habitat will typically only be used temporarily (Zwarts et al 2009). Previous tracking confirmed that turtle doves wintering in West Africa make movements of several hundreds of kilometers during the wintering season (Eraud et al 2013; Lormée et al. 2016). Our results confirm the use of more than one wintering site for the majority of tracked individuals (4 of 5) with a predominantly southward shift during the wintering period (Fig. 1). It is likely that the winter movements are linked to the availability of food resources, i.e., tracking food resources that become temporally available by the maturing and harvesting of cereal crops in different regions (Eraud et al. 2013; Lormée et al. 2016). Average sizes of $95 \%$ and $50 \%$ KUDs (65 and $5 \mathrm{~km}^{2}$, respectively) were very similar with the size of winter sites (95\% MCPs: 60 and $87 \mathrm{~km}^{2}$, 50\% MCPs: 2 and $3 \mathrm{~km}^{2}$ ) calculated by Lormée et al. (2016). The habitat mosaic used at wintering sites consisted predominantly of crop- and grassland as well as a more varying proportion of areas covered by trees or shrubs. The proportion of tree and shrub covered areas appears to be higher for individuals wintering in the Western part compared to the ones in Central and Eastern part of Western Africa (Fig. 3). However, this pattern should be verified with more individuals in order to derive possible connections between, e.g., survival, body condition, or migration performance and overwintering region and differing land cover types there.

\section{Niche tracking versus niche switching}

We still lack a general understanding whether seasonal migration occurs in order to track a specific niche between summer and winter distribution ranges, i.e., migrants following a fixed set of environmental conditions throughout the annual cycle (Zurell et al. 2018). The PCA in our analysis extracted ecological habitat parameters related to vegetation and biomass production to mainly determine $\mathrm{PC} 1$. This fits the suggestion that Afro-Palearctic migrating landbirds track the vegetation green-up in spring and depart before vegetation senescence in autumn (Briedis et al. 2020). The extracted parameters for PC1 might also be interpreted as a proxy for food availability, what would correspond to the observed winter movements, which are most likely connected to the tracking of different available food resources over time (Eraud et al. 2013; Lormée et al. 2016). PC2, that was more constant for both periods, was mainly determined by temperature (Supplementary Table 3). For breeding grounds, it was shown already, that mainly climate variables, in particular "minimum temperature in January" and "precipitation of the warmest quarter," shape distribution models of turtle doves (Marx and Quillfeldt 2018) and that distribution is linked to an isotherm of a minimum of $16-19^{\circ} \mathrm{C}$ in
July (Fisher et al. 2018). Plotting the habitat niches (Fig. 4) shows that the environmental parameters are more widely dispersed for data from the breeding grounds compared to more uniform parameters at the wintering grounds, indicating differences in the niche breadth for both seasons and a more pronounced intraspecific difference in individual habitat choice at the breeding compared to wintering sites. This matches the fact that turtle doves occur over a wide range of forest and agricultural landscapes at European breeding grounds, but winter along a relatively narrow and more uniform, with regard to climate and vegetation, latitudinal band along the Sahel and Sudan savannah.

The main conclusion to be drawn from the niche tracking approach is that habitat requirements and preferences determined at breeding sites cannot be assumed for wintering sites and vice versa but need to be investigated separately due to the apparent observed niche switching in turtle doves. A narrower niche breadth, during the wintering compared to the breeding season, might suggest that turtle doves might be more vulnerable to future changes, such as land cover conversion or climate changes, in their winter than in their breeding ranges.

\section{Migration and stopovers}

Like previous studies (Murton 1968; Lormée et al. 2016), our data clearly show that turtle doves are mainly nocturnal migrants. The migration durations shown by our tracked birds are similar to other studies (autumn migration: 21.3 and 22 days; spring migration: 28.3 and 20-21 days, Eraud et al. 2013; Lormée et al. 2016, respectively). Even if the mean duration did not vary remarkably between spring and autumn ( 27 and 25 days, respectively), the duration of autumn migration was more variable inter-individually (7-64 vs. 20-50 days), but also intra-individually (\#161050: spring migration: 20-23 days and autumn migration 7-18 days, Table 2). As migration consists of flight and refueling periods, the total migration duration is determined by flight speed as well as variables reflecting fuel deposition performance. The latter, e.g., total stopover duration, are expected to have a much stronger impact than flight behavior on the duration of migration (Houston 2000; Nilsson et al. 2013; Schmaljohann 2018). Our results show a similar mean speed flight during active spring and autumn migration (approx. 46 vs. $51 \mathrm{~km} / \mathrm{h}$, respectively) as well as a similar stopover duration (12.4 vs. 11.9 days).

On spring migration, turtle doves were expected to stop over in the southern border area of the Sahara to refuel prior to crossing the desert enabling them to cross the Sahara, North Africa, the Mediterranean Seas as well as much of Southern Europe without additional stopovers (Zwarts et al. 2009). Only individual \#181091 showed that behavior, staging in Mauritania, while the remaining individuals possibly 
may have fueled at their wintering sites already. Instead, we found that all complete spring migration tracks included a stopover in North Africa (Fig. 1). This is in line with the results of Eraud et al. (2013) and Lormée et al. (2016), showing that birds staged before crossing the Mediterranean Sea. As adult turtle doves have completed the flight-feather molt at that time, it is likely that these stopovers in North Africa are used to refuel before heading further north (Eraud et al. 2013), emphasizing the importance of these stopover sites for successful arrival at breeding grounds.

Contrary to the clear pattern during spring migration, the stopover pattern during autumn migration showed higher inter- and intraspecific variation. Importantly, in relation to current efforts on adaptive hunting management, the autumn migration of the majority of individuals (58.3\% and excluding the individuals with breeding sites in Italy even $70.0 \%$ ) included prolonged stopovers (>10 days) in Europe, e.g., in France and Spain (Western flyway) or for the CentralEastern flyway Slovakia and Hungary, representing the most important country for autumn stopovers (Supplementary Fig. 3). These stopovers as well as autumn migration movements match timewise with the legal hunting activities in the respective European countries (Fisher et al. 2018).

It is likely that the molt of the first inner primaries took place at the post-breeding and stopover molt sites (Demongin 2016) along with building up reserves for migration. A common suggestion for explaining this shift in habitat on the breeding area is that post-breeding adults might seek out for more abundant food resources and denser vegetation for cover, as they may be more vulnerable because of compromised flight capabilities while they molt (Vitz and Rodewald 2007; Tonra and Reudink 2018). Turtle dove \#161050 was the only carrying out an autumn migration without any stopover but staged during the other years (Table 2). Also the migration routes of \#161050 were not exactly the same over the years (Supplementary Fig. 1a). A larger inter-individual variation in autumn than in spring migration was also found in other tracked bird species (Alerstam et al. 2006; Vardanis et al. 2011; Stanley et al. 2012). This individual variation in migration routes may indicate that the birds navigate mainly by other means, e.g., responding to variation in environmental conditions, than a detailed route recapitulation based on the recognition of landmarks (Vardanis et al. 2011). Clearly more turtle dove tracks are needed to statistically confirm that the species might be quite flexible in space, i.e., flexibility in migration route.

By tagging different individuals in the same year as well as from the same breeding sites, we can show diverse movement patterns for individuals sharing a common breeding site. Individuals \#181089, \#181090, and \#181092 all tagged at the same forest in Brandenburg started the autumn migration with a difference of up to over 1 month (05.08, 27.08, and 13.09.2019, respectively) and followed different migration routes (Fig. 1). This was particularly notable in differing longitudes at which birds arrived at the African continent (ranging from $9.5,13.8$ to $18.0^{\circ} \mathrm{O}$ ). Likewise, three individuals from one capture site in Hesse (\#200350, \#200351, and \#200352) showed a similar variability in time for migration onset $(31.07,29.08$, and 05.09.2020, respectively) and migration routes (Fig. 1). In other bird species, individuals from one breeding area or colony also follow different migration routes (Bächler et al. 2010; Schmaljohann et al. 2012; Trierweiler et al. 2014; Wellbrock et al. 2017). The fact that different individuals from the same breeding site performed diverse movement patterns during autumn migration suggests that several suitable areas for overwintering coexist, assuming turtle doves taking different migration routes also spend the winter period in different sub-Saharan areas as suggested by our tracking results and ringing data (Marx et al. 2016). This indicates a rather weak linkage between breeding and non-breeding grounds, i.e., a rather weak migratory connectivity. A rather weak migratory connectivity is in line with the non-existent genetic structuring across flyways (Calderón et al. 2016).

In general, our results confirm the three main migration routes previously suggested based on mark-recovery data (Dimaki and Alivizatos 2014; Marx et al. 2016). However, compared to ring recoveries, the tracking data provide a more detailed picture of the routes. Thus, we show that not all individuals following the Western migration route fly along the strait of Gibraltar but cross the Mediterranean Sea already further east by leaving from the Spanish mainland, indicating that turtle doves do not necessarily avoid larger sea crossings. Moreover, the expected course of the Central flyway through Italy and Malta was not taken by \#200352, which instead crossed the sea further west through Corsica and Sardinia (Fig. 1).

The hypothesis for a loop migration pattern, i.e., using a flyway lying west or east of the spring route for autumn migration, in turtle doves hitherto assumed based on geolocator data (Eraud et al. 2013) is partly supported by our data. In particular, the partial tracks of \#161048 and \#161049 indicate a clockwise loop migration, i.e., an Eastern route for autumn migration and a Central route for spring migration. However, \#181091, following the Western route, \#161046 and \#161,050, following the Central route for both migratory directions, provide no evidence for a consistent loop migration pattern. These findings together with the ringing studies, which demonstrated a regular mixing between the Central and Eastern flyway (Marx et al. 2016), indicate that loop migration might be more common for turtle doves following the Eastern flyway in autumn than for individuals following the Western or Central flyway. Two main likely factors may result in loop migration patterns in some turtle doves: regional variations in habitat availability and foraging conditions during the two seasons (Tøttrup et al. 2008; 
Stach et al. 2016) and adaptation to prevailing wind patterns (Patchett and Cresswell 2020; Lisovski et al. 2021), such as different flight altitudes in relation to trade winds and antitrades during spring and autumn migration in the Sahara (Bruderer et al. 2018).

Turtle doves spend about two-thirds of the year away from their breeding grounds, at stopover sites, on active migration and in the wintering grounds, highlighting the importance of these periods in the life cycle when considering conservation efforts. Less strictly defined migration flyways, some individuals carrying out loop migration and an apparent rather weak migratory connectivity result in an overall observed pattern of migration occurring in a broad front instead of funneling at specific sites. Consequently, turtle doves should be considered as one (panmictic) population, spending time in many different countries during migration, demanding concerted conservation actions across all relevant countries to provide protection along all flyways in order to protect the entire population of turtle doves breeding in Europe.

Supplementary Information The online version contains supplementary material available at https://doi.org/10.1007/s00265-021-03082-5.

Acknowledgements We thank Charles Coleiro, Paulo Lago Barreiro, Tim Micallef, Edward Jenkins, Jennifer Greiner, Leslie Koch, and Hagen Deutschmann for help with fieldwork, capture, and tagging as well as Mark Gauci, the Maltese Ringing Scheme and BirdLife Malta for logistic support on Malta. We gratefully acknowledge the Naturschutz Bund Deutschland e.V. (BirdLife Germany), BirdLife Malta and the Hessische Gesellschaft für Ornithologie und Naturschutz (HGON) for funding and logistic support.

Author contributions YRS, BM, and PQ conceived the study. All authors planned and performed fieldwork. YRS, BM, and PQ designed methodology and conducted the analyses. All authors contributed critically to the manuscript draft.

Funding Open Access funding enabled and organized by Projekt DEAL. Financial support was received from the Naturschutz Bund Deutschland e.V. (BirdLife Germany) and BirdLife Malta for the Argos transmitters and fieldwork and the Hessische Gesellschaft für Ornithologie und Naturschutz (HGON) funded fieldwork in Hesse.

Data availability Data generated and/or analyzed during the current study are included in the published article and its supplementary information files.

\section{Declarations}

Conflict of interest The authors declare no competing interests.

Ethics approval All applicable institutional and/or national guidelines for the care and use of animals were followed. Capture, handling and tagging was carried out under license number BR029/16 of the Wild Bird Regulation Unit (WBRU) and the Maltese Environment and Resources Authority (ERA) and under licenses of the regional council Hesse (license number TVA-51/2017), including an ethical approval according to the national animal protection law (TierSchG $§ 7 \mathrm{a}$ ), and the state office for occupational safety, consumer protection and health, Brandenburg (license number 2347-11-2018).

Consent for publication All authors declare that they read the final version and give consent for the article to be published in Behavioral Ecology and Sociobiology.

Open Access This article is licensed under a Creative Commons Attribution 4.0 International License, which permits use, sharing, adaptation, distribution and reproduction in any medium or format, as long as you give appropriate credit to the original author(s) and the source, provide a link to the Creative Commons licence, and indicate if changes were made. The images or other third party material in this article are included in the article's Creative Commons licence, unless indicated otherwise in a credit line to the material. If material is not included in the article's Creative Commons licence and your intended use is not permitted by statutory regulation or exceeds the permitted use, you will need to obtain permission directly from the copyright holder. To view a copy of this licence, visit http://creativecommons.org/licenses/by/4.0/.

\section{References}

Alerstam T, Hake M, Kjellen N (2006) Temporal and spatial patterns of repeated migratory journeys by ospreys. Anim Behav 71:555-566. https://doi.org/10.1016/j.anbehav.2005.05.016

Bächler E, Hahn S, Schaub M, Arlettaz R, Jenni L, Fox JW, Afanasyev V, Liechti F (2010) Year-round tracking of small trans-saharan migrants using light-level geolocators. PLoS One 5:e9566. https:// doi.org/10.1371/journal.pone.0009566

Baessler C, Klotz S (2006) Effects of changes in agricultural land-use on landscape structure and arable weed vegetation over the last 50 years. Agric Ecosyst Environ 115:43-50. https://doi.org/10. 1016/j.agee.2005.12.007

BirdLife International (2019) Streptopelia turtur. The IUCN Red List of Threatened Species 2019. https://www.iucnredlist.org/species/ 22690419/154373407

Bivand R, Lewin-Koh N, Pebesma E et al (2020) maptools: tools for handling spatial objects. http://r-forge.r-project.org/projects/maptools/

Briedis M, Bauer S, Adamík P et al (2020) Broad-scale patterns of the Afro-Palaearctic landbird migration. Glob Ecol Biogeogr 29:722-735. https://doi.org/10.1111/geb.13063

Browne SJ, Aebischer NJ (2001) The role of agricultural intensification in the decline of the turtle dove Streptopelia turtur. English Nature Research Report 421, Peterborough

Browne SJ, Aebischer NJ (2003) Temporal changes in the migration phenology of turtle doves Streptopelia turtur in Britain, based on sightings from coastal bird observatories. J Avian Biol 34:65-71

Browne SJ, Aebischer NJ (2004) Temporal changes in the breeding ecology of European Turtle Doves Streptopelia turtur in Britain, and implications for conservation. Ibis 146:125-137. https://doi. org/10.1111/j.1474-919X.2004.00235.x

Browne SJ, Aebischer NJ, Yfantis G, Marchant JH (2004) Habitat availability and use by Turtle Doves Streptopelia turtur between 1965 and 1995: an analysis of Common Birds Census data. Bird Study 51:1-11. https://doi.org/10.1080/00063650409461326

Bruderer B, Peter D, Korner-Nievergelt F (2018) Vertical distribution of bird migration between the Baltic Sea and the Sahara. J Ornithol 159:315-336. https://doi.org/10.1007/s10336-017-1506-z

Calderón L, Campagna L, Wilke T et al (2016) Genomic evidence of demographic fluctuations and lack of genetic structure across flyways in a long distance migrant, the European turtle dove. BMC Evol Biol 16:237. https://doi.org/10.1186/s12862-016-0817-7 
Calenge C (2015) Home range estimation in R: the adehabitatHR package. https://cran.r-project.org/web/packages/adehabitatHR

Chiatante G, Porro Z, Meriggi A (2020) The importance of riparian forests and tree plantations for the occurrence of the European Turtle Dove Streptopelia turtur in an intensively cultivated agroecosystem. Bird Conserv Int:1-15.https://doi.org/10.1017/S0959 270920000532

Copernicus Land Monitoring Service (2021) Corine Land Cover (CLC) 2018, Version 2020_20u1. https://land.copernicus.eu/pan-europ ean/corine-land-cover/clc2018

Dallimer M, Tinch D, Acs S, Hanley N, Southall HR, Gaston KJ, Armsworth PR (2009) 100 years of change: examining agricultural trends, habitat change and stakeholder perceptions through the 20th century. J Appl Ecol 46:334-343. https://doi.org/10. 1111/j.1365-2664.2009.01619.x

Demongin L (2016) Identification guide to birds in the hand. Beauregard-Vendon, pp 184-185

Dias S, Moreira F, Beja P, Carvalho M, Gordinho L, Reino L, Oliveira V, Rego F (2013) Landscape effects on large-scale abundance patterns of turtle-doves Streptopelia turtur in Portugal. Eur J Wildl Res 59:531-541. https://doi.org/10.1007/s10344-013-0702-2

Dimaki M, Alivizatos H (2014) Ringing studies of the turtle dove Streptopelia turtur (Aves: Columbidae) during passage through Antikythera Island, southwestern Greece. J Nat Hist 49:419-427. https://doi.org/10.1080/00222933.2013.830790

Dodge S, Bohrer G, Weinzierl R, Davidson SC, Kays R, Douglas D, Cruz S, Han J, Brandes D, Wikelski M (2013) The Environmental-Data Automated Track Annotation (Env-DATA) System: linking animal tracks with environmental data. Mov Ecol 1:3. https:// doi.org/10.1186/2051-3933-1-3

Douglas DC, Weinzierl R, Davidson SC, Kays R, Wikelski M, Bohrer G (2012) Moderating Argos location errors in animal tracking data. Methods Ecol Evol 3:999-1007. https://doi.org/10.1111/j. 2041-210X.2012.00245.x

Dunn JC, Morris AJ (2012) Which features of UK farmland are important in retaining territories of the rapidly declining Turtle Dove Streptopelia turtur? Bird Study 59:394-402. https://doi.org/10. 1080/00063657.2012.725710

Dunn JC, Morris AJ, Grice PV, Peach WJ (2020) Effects of seed-rich habitat provision on territory density, home range and breeding performance of European Turtle Doves Streptopelia turtur. Bird Conserv Int:1-20. https://doi.org/10.1017/S0959270920000635

EEA (2020) European Environment Agency: Forest dynamics in Europe and their ecological consequences. https://www.eea. europa.eu/themes/biodiversity/forests

Epanechnikov VA (1969) Non-parametric estimation of a multivariate probability density. Theor Probab Appl 14:153-158. https://doi. org/10.1137/1114019

Eraud C, Boutin JM, Riviere M, Brun J, Barbraud C, Lormée H (2009) Survival of Turtle Doves Streptopelia turtur in relation to western Africa environmental conditions. Ibis 151:186-190. https://doi. org/10.1111/j.1474-919X.2008.00876.x

Eraud C, Rivière M, Lormée H, Fox JW, Ducamp JJ, Boutin JM (2013) Migration routes and staging areas of trans-Saharan turtle doves appraised from light-level geolocators. PLoS One 8:e59396. https://doi.org/10.1371/journal.pone.0059396

ESA CCI Land Cover project (2021) S2 prototype LC 20m map of Africa 2016. https://2016africalandcover20m.esrin.esa.int

Fair J, Paul E, Jones J (2010) Guidelines to the use of wild birds in research. Ornithological Council, Washington DC

Fisher I, Ashpole J, Scallan D et al (2018) International single species action plan for the conservation of the European Turtle-dove Streptopelia turtur (2018 to 2028). European Commission Technical Report xxx-2018

Gerard F, Petit S, Smith G et al (2010) Land cover change in Europe between 1950 and 2000 determined employing aerial photography.
Prog Phys Geogr 34:183-205. https://doi.org/10.1177/03091 33309360141

Glutz Von Blotzheim UN, Bauer KM (1987) Handbuch der Vögel Mitteleuropas. Band 9. Columbiformes - Piciformes. AULA-Verlag, Wiesbaden

Gómez C, Tenorio EA, Montoya P, Cadena CD (2016) Niche-tracking migrants and niche-switching residents: evolution of climatic niches in New World warblers (Parulidae). Proc R Soc B 283:20152458. https://doi.org/10.1098/rspb.2015.2458

Griffiths R, Double MC, Orr K, Dawson RJG (1998) A DNA test to sex most birds. Mol Ecol 7:1071-1075. https://doi.org/10.1046/j. 1365-294x.1998.00389.x

Hahn S, Bauer S, Liechti F (2009) The natural link between Europe and Africa - 2.1 billion birds on migration. Oikos 118:624-626. https://doi.org/10.1111/j.1600-0706.2009.17309.x

Hanane S (2012) Do age and type of plantings affect turtle dove Streptopelia turtur nest placement in olive agro-ecosystems? Ethol Ecol Evol 24:284-293. https://doi.org/10.1080/03949370.2011. 634439

Houston AI (2000) The strength of selection in the context of migration speed. Proc R Soc Lond B 267:2393-2395. https://doi.org/ 10.1098/rspb.2000.1296

Kapusta P (2015) Points2One. QGIS Plugin. https://plugins.qgis.org/ plugins/points2one/

Lisovski S, Neumann R, Albrecht T et al (2021) The Indo-European flyway: opportunities and constraints reflected by Common Rosefinches breeding across Europe. J Biogeogr. published online. https://doi.org/10.1111/jbi.14085

Lormée H, Barbraud C, Peach W, Carboneras C, Lebreton JD, MorenoZarate L, Bacon L, Eraud C (2019) Assessing the sustainability of harvest of the European Turtle-dove along the European western flyway. Bird Conserv Int:1-16.https://doi.org/10.1017/S0959 270919000479

Lormée H, Boutin JM, Pinaud D, Bidault H, Eraud C (2016) Turtle Dove Streptopelia turtur migration routes and wintering areas revealed using satellite telemetry. Bird Study 63:425-429. https:// doi.org/10.1080/00063657.2016.1185086

Lutz M (2007) Management plan for turtle dove (Streptopelia turtur) 2007-2009. European Commission, Technical Report 007. https:// ec.europa.eu/environment/nature/conservation/wildbirds/hunting/ docs/turtle_dove.pdf

Mallet-Rodrigues F (2012) Replacement and growth of primary feathers in captive rock pigeons, Columba livia (Aves: Columbidae). Zoologia 29:121-125. https://doi.org/10.1590/S1984-4670201200 0200004

Mansouri I, Al-Sadoon MK, Rochdi M, Paray BA, Dakki M, Elghadraoui $L$ (2019) Diversity of feeding habitats and diet composition in the turtle doves Streptopelia turtur to buffer loss and modification of natural habitats during breeding season. Saudi J Biol Sci 26:957-962. https://doi.org/10.1016/j.sjbs.2018.11.006

Marx M, Korner-Nievergelt F, Quillfeldt P (2016) Analysis of ring recoveries of European Turtle Doves Streptopelia turtur - flyways, migration timing and origin areas of hunted birds. Acta Ornithol 51:55-70. https://doi.org/10.3161/00016454AO2016.51.1.005

Marx M, Quillfeldt P (2018) Species distribution models of European Turtle Doves in Germany are more reliable with presence only rather than presence absence data. Sci Rep 8:16898. https://doi. org/10.1038/s41598-018-35318-2

Murton RK (1968) Breeding, migration and survival of Turtle Doves. Brit Birds 61:193-212

Nakazawa Y, Peterson A, Martínez-Meyer E, Navarro-Sigüenza A (2004) Seasonal niches of nearctic-neotropical migratory birds: implications for the evolution of migration. Auk 121:610-618. https://doi.org/10.2307/4090425

Nathan R, Getz WM, Revilla E, Holyoak M, Kadmon R, Saltz D, Smouse PE (2008) A movement ecology paradigm for 
unifying organismal movement research. Proc Natl Acad Sci U S A 105:19052-19059. https://doi.org/10.1073/pnas.0800375105

Nilsson C, Klaassen RHG, Alerstam T (2013) Differences in speed and duration of bird migration between spring and autumn. Am Nat 181:837-845. https://doi.org/10.1086/670335

Pagen RW, Thompson FR, Burhans DE (2000) Breeding and postbreeding habitat use by forest migrant songbirds in the Missouri Ozarks. Condor 102:738-747. https://doi.org/10.1093/condor/ 102.4.738

Patchett R, Cresswell W (2020) Regional wind patterns likely shape a seasonal migration detour. J Avian Biol 51:e02466. https://doi. org/10.1111/jav.02466

Pebesma E (2020) sp Classes and Methods for Spatial Data v1.4-1. https://www.rdocumentation.org/packages/sp

PECBMS (2020) Population Trends of Common European Breeding Birds. https://pecbms.info/trends-and-indicators/species-trends/ species/streptopelia-turtur/

Pillar AG, Marra PP, Flood NJ, Reudink MW (2016) Moult migration in Bullock's orioles (Icterus bullockii) confirmed by geolocators and stable isotope analysis. J Ornithol 157:265-275. https://doi. org/10.1007/s10336-015-1275-5

Ponti R, Arcones A, Ferrer X, Vieites DR (2020) Seasonal climatic niches diverge in migratory birds. Ibis 162:318-330. https://doi. org/10.1111/ibi.12784

QGIS.org (2016) QGIS Geographic Information System. Open Source Geospatial Foundation Project. https://www.qgis.org/en/site/

R Development Core Team (2018) R: a language and environment for statistical computing. R Foundation for Statistical Computing, Vienna, Austria. http://www.R-project.org

Schmaljohann H (2018) Proximate mechanisms affecting seasonal differences in migration speed of avian species. Sci Rep 8:4106. https://doi.org/10.1038/s41598-018-22421-7

Schmaljohann H, Buchmann M, Fox JW, Bairlein F (2012) Tracking migration routes and the annual cycle of a trans-Sahara songbird migrant. Behav Ecol Sociobiol 66:915-922. https://doi.org/10. 1007/s00265-012-1340-5

Stach R, Kullberg C, Jakobsson S, Ström K, Fransson T (2016) Migration routes and timing in a bird wintering in south Asia, the common rosefinch Carpodacus erythrinus. J Ornithol 157:671-679. https://doi.org/10.1007/s10336-016-1329-3

Stanley CQ, MacPherson M, Fraser KC, McKinnon EA, Stutchbury BJM (2012) Repeat tracking of individual songbirds reveals consistent migration timing but flexibility in route. PLoS One 7:e40688. https://doi.org/10.1371/journal.pone.0040688

Tingley MW, Monahan WB, Beissinger SR, Moritz C (2009) Birds track their Grinnellian niche through a century of climate change.
Proc Natl Acad Sci U S A 106:19637-19643. https://doi.org/10. 1073/pnas.0901562106

Tonra CM, Reudink MW (2018) Expanding the traditional definition of molt-migration. Auk 135:1123-1132. https://doi.org/10.1642/ AUK-17-187.1

Tøttrup AP, Thorup K, Rainio K, Yosef R, Lehikoinen E, Rahbek C (2008) Avian migrants adjust migration in response to environmental conditions en route. Biol Lett 4:685-688. https://doi.org/ 10.1098/rsbl.2008.0290

Trierweiler C, Klaassen RHG, Drent RH, Exo KM, Komdeur J, Bairlein F, Koks BJ (2014) Migratory connectivity and populationspecific migration routes in a long-distance migratory bird. Proc R Soc B 281:20132897. https://doi.org/10.1098/rspb.2013.2897

van der Graaf AJ, Stahl J, Klimkowska A, Bakker JP, Drent RH (2006) Surfing on a green wave - how plant growth drives spring migration in the Barnacle Goose Branta leucopsis. Ardea 94:567-577

Vardanis Y, Raymond KHG, Strandberg R, Alerstam T (2011) Individuality in bird migration: routes and timing. Biol Lett 7:502-505. https://doi.org/10.1098/rsbl.2010.1180

Venables WN, Ripley BD (2002) Modern Applied Statistics with S, 4 th edn. Springer, New York

Vitz AC, Rodewald AD (2007) Vegetative and fruit resources as determinants of habitat use by mature-forest birds during the postbreeding period. Auk 124:494-507. https://doi.org/10.1093/auk/ 124.2.494

Wellbrock AHJ, Bauch C, Rozman J, Witte K (2017) Same procedure as last year? Repeatedly tracked swifts show individual consistency in migration pattern in successive years. J Avian Biol 48:897-903. https://doi.org/10.1111/jav.01251

Wesche K, Krause B, Culmsee H, Leuschner C (2012) Fifty years of change in Central European grassland vegetation: Large losses in species richness and animal-pollinated plants. Biol Conserv 150:76-85. https://doi.org/10.1016/j.biocon.2012.02.015

Zúñiga D, Falconer J, Fudickar A, Jensen W, Schmidt A, Wikelski M, Partecke J (2016) Abrupt switch to migratory night flight in a wild migratory songbird. Sci Rep 6:34207. https://doi.org/10. 1038/srep34207

Zurell D, Gallien L, Graham CH, Zimmermann NE (2018) Do longdistance migratory birds track their niche through seasons? J Biogeogr 45:1459-1468. https://doi.org/10.1111/jbi.13351

Zwarts L, Bijlsma R, van der Kamp B, Wimenga E (2009) Living on the edge: wetlands and birds in a changing Sahel. KNNV Publishing, Zeist

Publisher's note Springer Nature remains neutral with regard to jurisdictional claims in published maps and institutional affiliations.

\section{Authors and Affiliations}

\section{Yvonne R. Schumm ${ }^{1} \cdot$ Benjamin Metzger ${ }^{2} \cdot$ Eric Neuling $^{3} \cdot$ Martin Austad $^{4} \cdot$ Nicholas Galea $^{4} \cdot$ Nicholas Barbara $^{4}$. Petra Quillfeldt ${ }^{1}$}

1 Department of Animal Ecology and Systematics, Justus Liebig University, Heinrich-Buff-Ring 26-32, 35392 Giessen, Germany

2 26/1 Immaculate Conception Street, Gzira GZR 1141, Malta
3 Naturschutzbund Deutschland E. V. (NABU), Charitéstraße 3, 10117 Berlin, Germany

4 Birdlife Malta, 57/28 Marina Court, Triq 1-Abate Rigord, Ta’ Xbiex, Malta 